\title{
Flora de um Brejo de Altitude na escarpa oriental do planalto da Borborema, PE, Brasil ${ }^{1}$
}

\author{
Maria Jesus Nogueira RodaR, ${ }^{4}$, Margareth Ferreira Sales ${ }^{2}$, Marcos José da Silva² e \\ Alexandre Gomes da Silva ${ }^{3}$
}

Recebido em 17/11/2004. Aceito em 05/05/2005

\begin{abstract}
RESUMO - (Flora de um Brejo de Altitude na escarpa oriental do planalto da Borborema, PE, Brasil). Os estudos nas florestas montanas nordestinas (brejos de altitude) indicam que as ombrófilas apresentam elevada riqueza de espécies e são mais relacionadas com a floresta ombrófila de terras baixas. Considerando o desconhecimento sobre as florestas ombrófilas sub-montanas, foi realizado o levantamento do Brejo de Bonito, Pernambuco, com o objetivo de conhecer seu perfil florístico. São apresentadas informações sobre o coletor/número, hábito e padrão de distribuição de cada espécie. Os resultados foram comparados a 22 levantamentos da Floresta Atlântica (latu sensu) nordestina. No brejo de Bonito foram coletadas 217 espécies, distribuídas em 65 famílias. Dessas, cerca de 50\% são citados em outras florestas montanas de Pernambuco e de terras baixas de Pernambuco e da Bahia. A maior parte das espécies encontradas tem distribuição na América do Sul, ocorrendo desde a porção norte, penetrando na costa leste brasileira e também na porção central do Brasil e, às vezes, no domínio do semi-árido, nos Brejos de Altitude. Outra porção representativa distribui-se desde a América Central até a porção centronorte da América do Sul, com poucas ocorrendo também na parte sul da América do Norte (Estados Unidos e México).
\end{abstract}

Palavras-chave : floresta ombrófila sub-montana, nordeste do Brasil, brejo de altitude, padrão de distribuição

\begin{abstract}
Floristics of an upland forest in the oriental slope of the Borborema plateau, Pernambuco State, Brazil). Studies in the northeastern upland forests (brejo de altitude) indicate that the humid ones show higher richness of species and have more floristic simalarity with the lowland humid forests. Considering the lack of data about humid sub-montane forests, a survey was carried out in the upland forest of Bonito, Pernambuco, aiming to identify their floristic composition. Voucher, habit, and pattern of distribution of each species are presented. The results were compared with 22 surveys in the northeastern Atlantic Rainforest (latu sensu). Two hundred and seventeen species, distributed in 65 families, were sampled at the study area. Among those, 50\% were cited in other upland forests and lowland forests in Pernambuco and Bahia States. The majority of species are scattered along South America, occurring from the north portion, penetrating through the Atlantic coast, as well as in the Brazilian central plateau, and sometimes reaching the semi-arid regions within the upland forests. Another important group of species are distributed starting at Central America to the middle region of South America, with a few occurring also in the south of North America (United States and Mexico).
\end{abstract}

Key words: sub-montane ombrophilous forest, Northeastern Brazil, upland forest, distribution pattern

\section{Introdução}

A Floresta Atlântica brasileira se estende ao longo da costa, de $07^{\circ} \mathrm{S}$ a $23^{\circ} \mathrm{S}$, e é composta por mosaico de diferentes fisionomias e floras sobre grande diversidade ambiental. Baseado no critério de endemismo específico e grau de degradação, aquela floresta foi identificada como um dos pontos mais críticos (hottest hotspots) para prioridades de conservação por Myers et al. (2000), apresentando número estimado de 20.000 espécies de plantas.
Sob a perspectiva fitogeográfica, a Floresta Atlântica pode ser dividida em dois conjuntos, Sudeste/ Sul e Nordeste, cada um com alta percentagem de endemismo (Rizzini 1979). Ainda sobre sua distribuição, a Floresta Atlântica pode penetrar no bioma Cerrado, localizado no Brasil central, através de cursos de água (Oliveira-Filho \& Ratter 2000) e no bioma Caatinga, no topo de serras e planaltos do semi-árido nordestino (Tavares et al. 2000).

Das diferentes tipologias encontradas na Floresta Atlântica nordestina, as florestas situadas em serras e

\footnotetext{
1 Trabalho financiado pelo projeto "Flora e vegetação de um remanescente de floresta ombrófila sub-montana no nordeste do Brasil" (Fundação o Boticário de Proteção à Natureza - Processo 5920002)

2 Universidade Federal Rural de Pernambuco, Departamento de Biologia, Rua Dom Manoel de Medeiros s/n. Dois Irmãos, CEP 52171-900, Recife, PE, Brasil

3 Universidade Federal Rural de Pernambuco, Herbário Professor Vasconcelos-Sobrinho, Rua Dom Manoel de Medeiros s/n, Dois Irmãos, CEP 52171-900, Recife, PE, Brasil

4 Autor para correspondência: mrodal@terra.com.br
} 
planaltos do semi-árido, localmente chamadas Brejos de Altitude, são ainda pouco conhecidas (Tavares et al. 2000). São ilhas florestais mais ou menos úmidas, em função de sua condição climática peculiar, já que o relevo cria uma barreira às massas de ar, que acabam depositando umidade nas vertentes à barlavento, grotões e vales de serras (Andrade-Lima 1982). Podem ser classificadas como montanas, quando situadas acima de $600 \mathrm{~m}$, ou sub-montanas, entre 100 e $600 \mathrm{~m}$ (Veloso et al. 1991), variando de ombrófilas a estacionais.

Dos Estados nordestinos, Pernambuco apresenta o maior número de levantamentos quantitativos em formações florestais. Como resultado, sabe-se que há grande variação florística relacionada aos elementos climáticos (precipitação, temperatura, vento, etc.) e a diversos fatores fisiográficos (orografia e efeito da continentalidade). A precipitação decresce para o interior (para o oeste), diminuindo de $2.000 \mathrm{~mm}^{-1}$ ano $^{-1}$ nas terras baixas próximas à costa Atlântica, onde predomina a floresta ombrófila, para 1.200-1.000 mm ano ${ }^{-1}$ nos níveis do cristalino que antecedem o planalto da Borborema, onde se destacam florestas estacionais e ombrófilas, que se diferenciam em função da altitude e exposição das encostas às massas de ar úmido vindas do litoral. No planalto da Borborema propriamente dito, a precipitação é variável, sendo possível encontrar desde Caatinga (Alcoforado-Filho et al. 2003) até florestas ombrófilas (Tavares et al. 2000). Finalmente, descendo o planalto em direção à oeste, a vegetação da Caatinga predomina em áreas mais baixas, situadas na depressão semi-árida, onde a precipitação está em torno de $500 \mathrm{~mm}$ (Jacomine et al. 1973; Rodal 2002). De modo geral, as temperaturas são muito elevadas nas áreas interioranas, exceto no planalto da Borborema que apresenta temperaturas ligeiramente mais baixas, especialmente durante a noite.

Os estudos quantitativos nas florestas montanas realizados por Tavares et al. (2000) e E.M.N. Ferraz (dados não publicados) indicam que as florestas ombrófilas montanas apresentam elevada riqueza de espécies e são relacionados com a floresta ombrófila de terras baixas. Todavia, pouco ou quase nada se sabe a respeito das florestas ombrófilas sub-montanas.

Considerando o desconhecimento das florestas ombrófilas sub-montanas da região, este trabalho tem por objetivo responder às seguintes questões: Qual a composição de uma floresta ombrófila sub-montana? Quanto dessa flora é compartilhada com outras florestas da região? e Quais os principais padrões de distribuição das espécies dessa floresta?

\section{Material e métodos}

A Mata do Brejão (08²9'40"S e 3541'45”'W) situa-se no chamado Brejo de Bonito (Fig. 1), série de remanescentes florestais localizados no município de Bonito, microrregião homogênea do Brejo Pernambucano (Rodal et al. 1998), a qual está inserida entre zonas fisiográficas distintas, a da Mata, mais úmida, e a do sertão, mais seca. Do ponto de vista geomorfológico, os terrenos estão situados na escarpa oriental do planalto da Borborema. A altitude varia de 450-500 m e a precipitação média anual é de $1.100 \mathrm{~mm}$. Trata-se de um remanescente que sofreu exploração seletiva e que a aproximadamente cinco anos está sendo preservado, segundo informações dos moradores do entorno

De março/2001 a fevereiro/2002 foram realizadas excursões mensais para coleta de material botânico no remanescente da Mata do Brejão. Todo material foi processado e tombado no herbário Professor Vasconcelos Sobrinho (PEUFR), da Universidade Federal Rural de Pernambuco, seguindo as normas técnicas recomendadas por Mori et al. (1989). As identificações foram realizadas por meio de bibliografia especializada e por comparação com exsicatas identificadas por especialistas e depositadas no herbário PEUFR, onde também está depositada a coleção de referência dos Brejos de Altitude Pernambuco.

A partir da identificação, foi elaborada a lista das famílias e espécies, organizada de acordo com o sistema de Cronquist (1981) com informações do coletor, número e hábito. A essa lista foram adicionadas as espécies registradas por Sales et al. (1998) em diferentes remanescentes de floresta ombrófila do município de

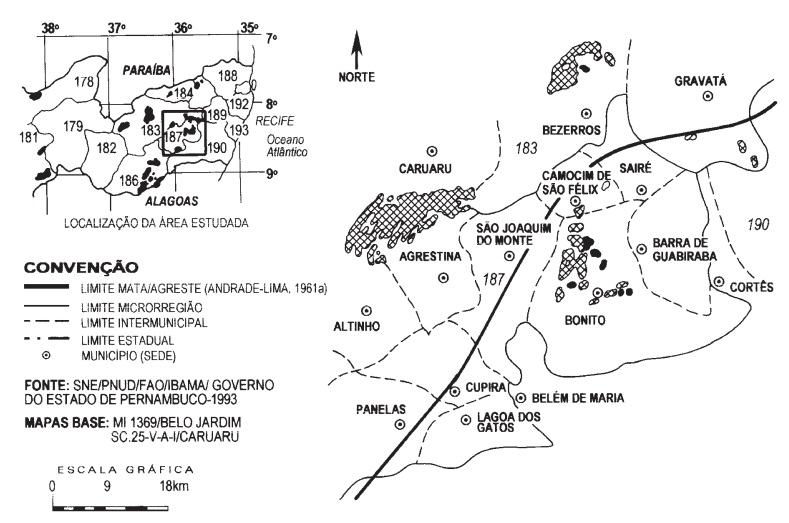

Figura 1. Localização dos remanescentes florestais no município de Bonito, PE, Brasil. $\$$ = Porte arbóreo fechado; $\boldsymbol{\square}=$ Porte arbustivo arbóreo. Fonte: Rodal et al. (1998) 
Bonito (Mata da Prefeitura, Mata da Maguary, Mata do Assentamento), todas com altitude e posição geográfica similar à Mata de Brejão. As espécies listadas foram classificadas quanto à sua distribuição empregando o sistema de Cabrera \& Willink (1980). Adicionalmente, a distribuição das espécies foi investigada com a análise de bibliografias de grupos taxonômicos e levantamentos florísticos.

Os resultados da lista florística geral de Bonito foram comparados a 22 levantamentos da Floresta Atlântica nordestina (latu sensu), sendo cinco em floresta estacional montana de Pernambuco (Correia 1996; Ferraz et al. 1998; Moura \& Sampaio 2001; L.M. Nascimento, dados não publicados; Rodal \& Nascimento 2002); uma em floresta estacional de terras baixas da Paraíba (Lima 2002); uma em floresta estacional de terras baixas de Pernambuco (Andrade $\&$ Rodal 2004); uma em floresta estacional de terras baixas do Rio Grande do Norte (Cestaro \& Soares 2004); duas em floresta ombrófila montana de Pernambuco (Tavares et al. 2000; E.M.N. Ferraz, dados não publicados); seis em floresta ombrófila de terras baixas de Pernambuco e Paraíba (M.R.V. Barbosa, dados não publicados; A.C.B. Lins e Silva \& M.J.N. Rodal, dados não publicados; Guedes 1998; A.C.S. Ramos, dados não publicados; Siqueira et al. 2001; A.G. Silva, dados não publicados); quatro em floresta ombrófila de terras baixas de Bahia (NYBG 2004a, b, c, d); dois em restinga de Pernambuco (J.R. Cantarelli, dados não publicados; S.S. Lira, dados não publicados). Todos os levantamentos em florestas montanas de Pernambuco tiveram suas listas ampliadas de acordo com as espécies citadas por Sales et al. (1998).

\section{Resultados}

Florística de Bonito - Na Mata do Brejão foram coletadas 102 espécies distribuídas por 52 famílias (Tab. 1), com predomínio de arbóreas $(44,1 \%)$, seguida por ervas $(13,7 \%)$ e arbustos com $11,7 \%$ cada. Considerando também as espécies coletas por Sales et al. (1998) para outros remanescentes de Bonito, há registro de um total de 217 espécies, distribuídas por 65 famílias (Tab. 1).

As famílias com maior número de espécies foram: Asteraceae e Euphorbiaceae com 14 espécies cada, seguidas por Melastomataceae e Rubiaceae (13 spp. cada), Solanaceae (dez spp.), Fabaceae (nove spp.), Caesalpiniaceae, Mimosaceae, Poaceae, Myrtaceae (oito spp. cada) e Cyperaceae (seis spp.).
No componente arbóreo dos diferentes fragmentos de Bonito (Mata do Brejão e Sales et al. 1998) foram coletadas 53 espécies, distribuídas em 22 famílias, com destaque para: Mimosaceae e Myrtaceae com seis espécies cada, seguida por Melastomataceae (cinco spp.) e Sapindaceae e Fabaceae (quatro spp. cada), (Tab. 1). Pela maior altura pode-se citar: Tapirira guianensis e Thyrsodium spruceanum (Anacardiaceae), Schefflera morototoni (Araliaceae), Bowdichia virgilioides (Fabaceae) e Simarouba amara (Simaroubaceae). No componente arbóreo mais baixo pode-se destacar: Croton floribundus (Euphorbiaceae), Lacistema robustum (Lacistemaceae) e Myrcia tomentosa (Myrtaceae).

No componente herbáceo dos diferentes fragmentos há registro de 48 espécies, distribuídas em 26 famílias, com destaque para Poaceae (oito spp.), Cyperaceae (seis spp.), Eupborbiaceae (quatro spp.) e Rubiaceae (três spp.) (Tab. 1). A maior parte das ervas da Mata do Brejão foi coletada na borda ou em clareiras no interior da floresta como: Costus spiralis (Costaceae) e Bomarea salsilloides (Alstroemeriaceae), etc. Outras como Habenaria obtusa e $H$. cf. cryptophylla (Orchidaceae) são típicas das áreas sombreadas do interior da floresta.

No estrato subarbustivo ocorreram 43 espécies, com maior riqueza em Asteraceae (oito spp.), Melastomataceae e Euphorbiaceae (quatro spp. cada) e Rubiaceae, Sterculiaceae e Solanaceae (três spp. cada) (Tab. 1). Os arbustos respondem por 40 espécies, sendo Solanaceae (6 spp. ) Rubiaceae (cinco spp.) e Caesalpiniaceae (quatro spp.), as famílias com maior riqueza de espécies.

A maioria dos arbustos e subarbustos da Mata do Brejão ocorreu no entorno ou trilhas da floresta como: Chamaecrista rotundifolia (Caesalpiniaceae), Vismia guianensis (Clusiaceae), Solanum asperum, S. baturitense e S. paniculatum (Solanaceae), Aegiphila sellowiana (Verbenaceae), entre outras.

Foram registradas 23 espécies de trepadeiras e lianas distribuídas por 15 famílias, sendo Cucurbitaceae com quatro espécies, das quais três pertencem ao gênero Gurania e Sapindaceae (três ssp.), as famílias mais representativas. As demais famílias ocorrem com uma ou duas espécies (Tab. 1). Finalmente, no componente das epífitas ocorreram quatro famílias, destacando-se Orchidaceae (4 spp.), Viscaceae (três spp.) e Araceae (duas spp.), respectivamente.

Entre as trepadeiras e lianas, pode-se observar que táxons como Momordica charantia (Cucurbitaceae) e Thunbergia alata (Acanthaceae) são bastante 


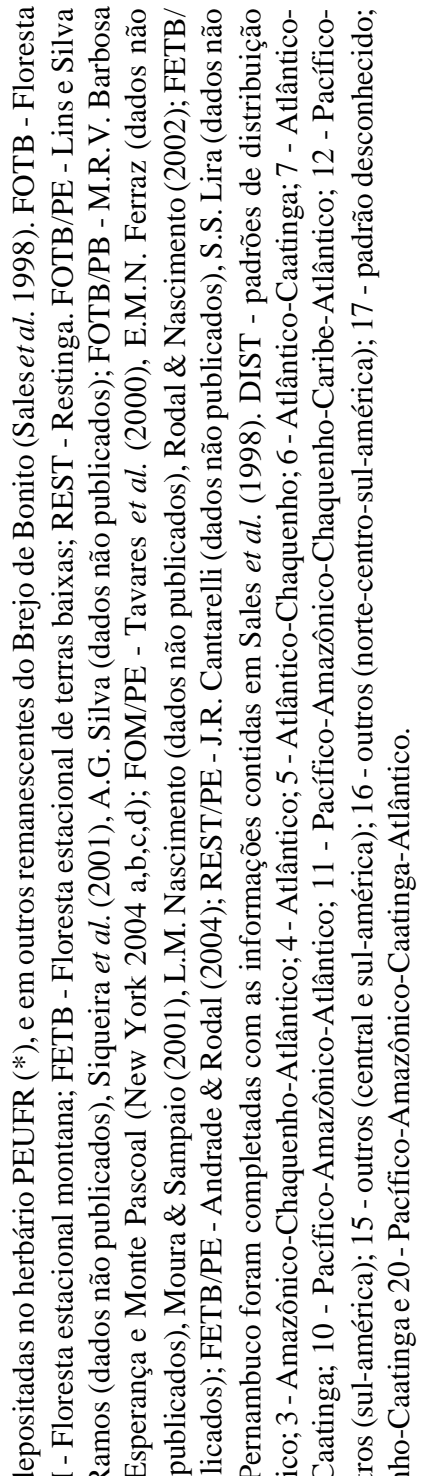

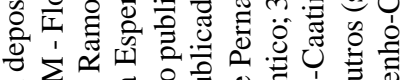

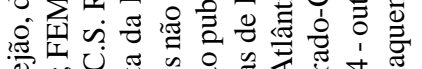

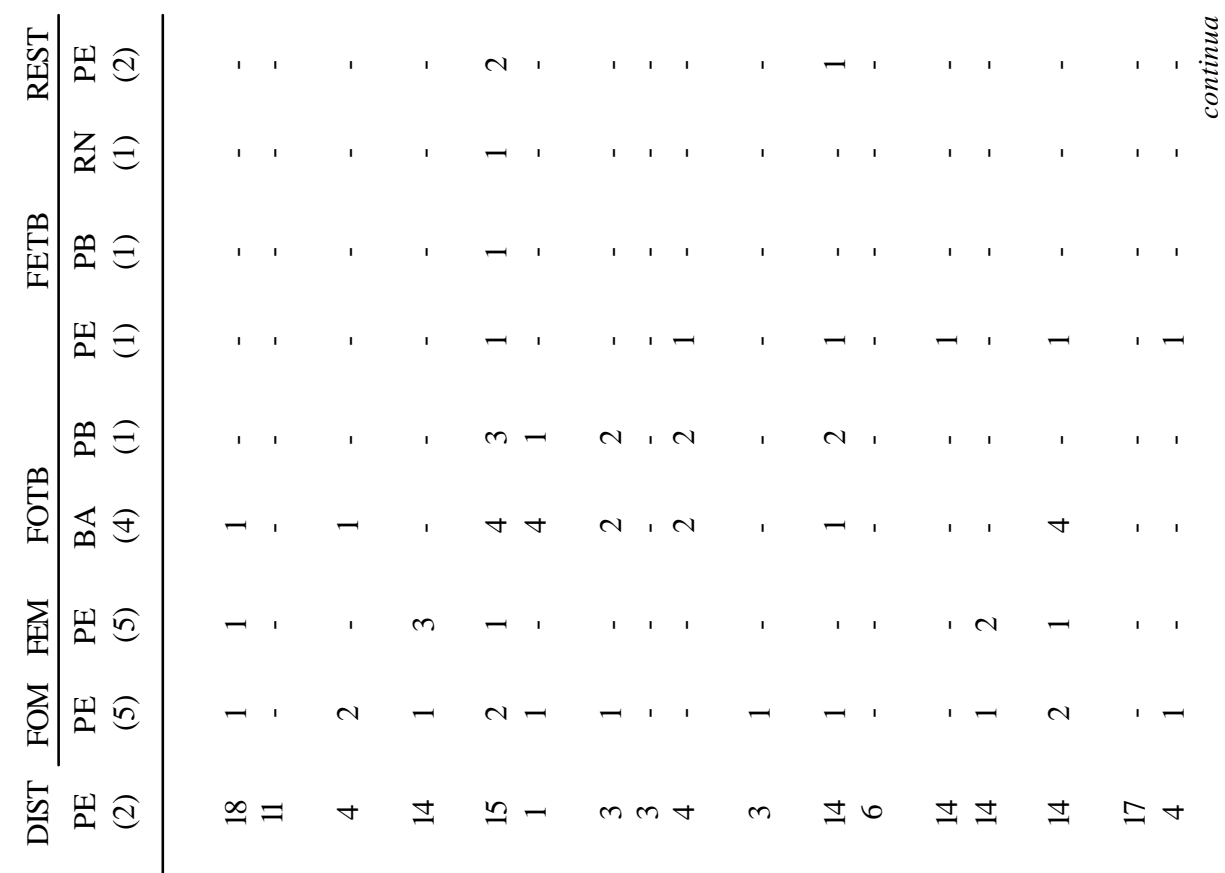

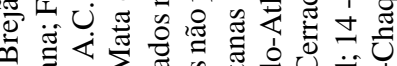

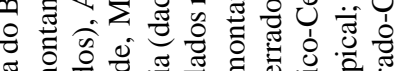

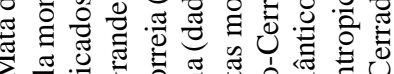

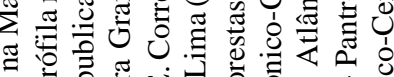

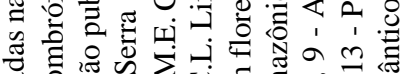

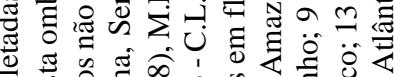

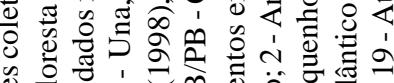

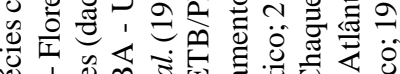

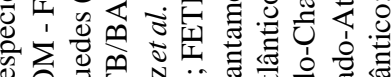

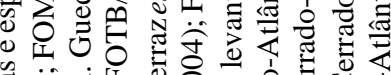

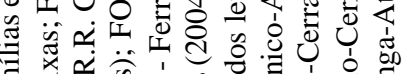

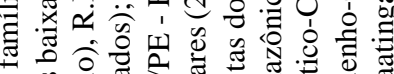

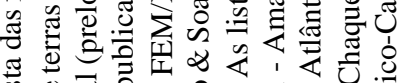

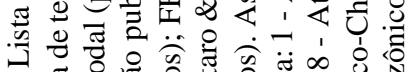

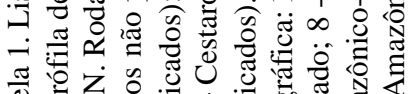

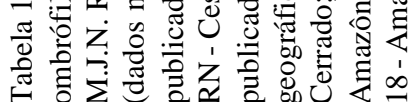

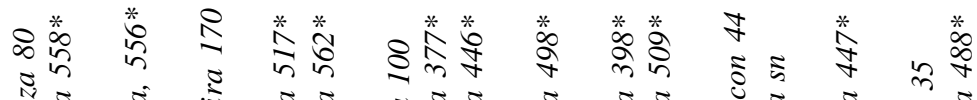

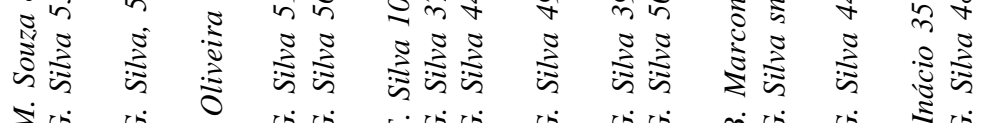
ن்

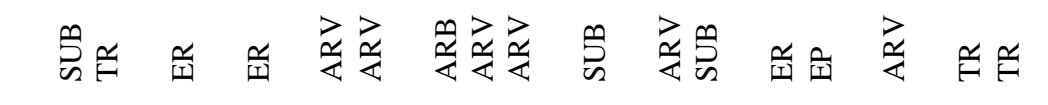




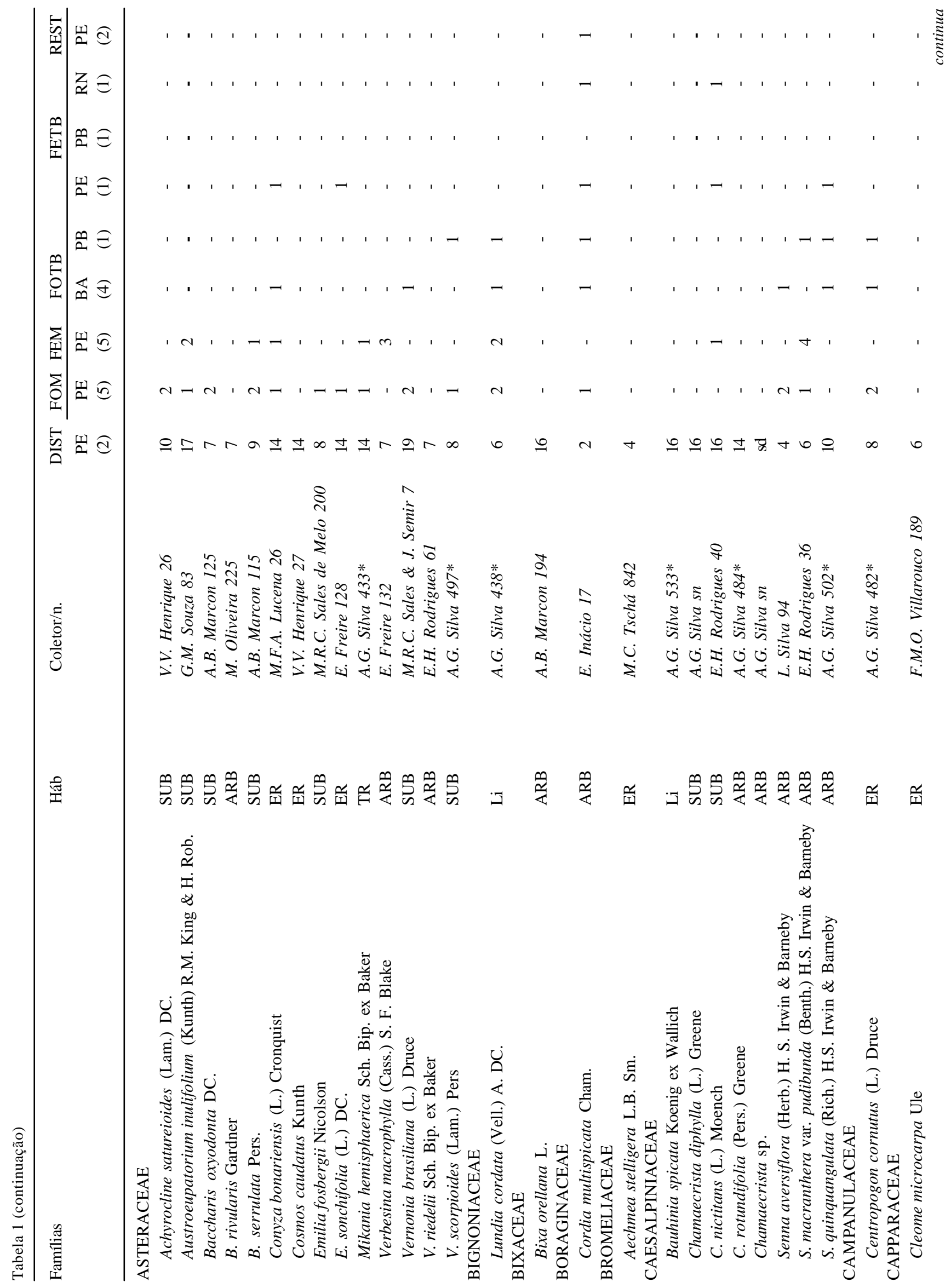




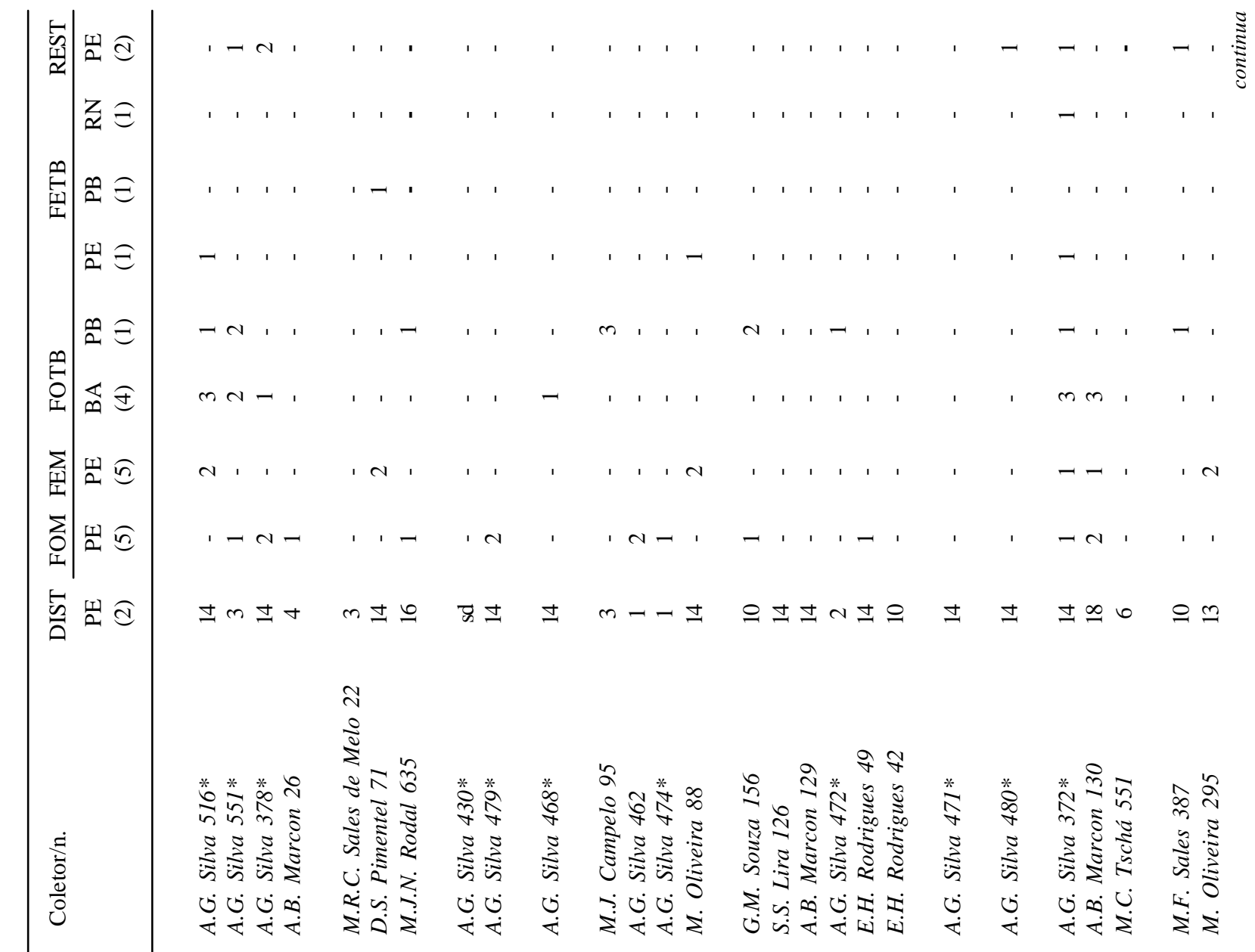

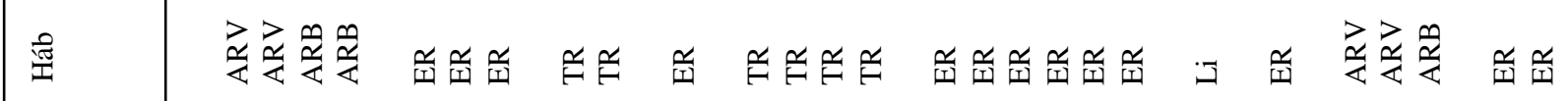

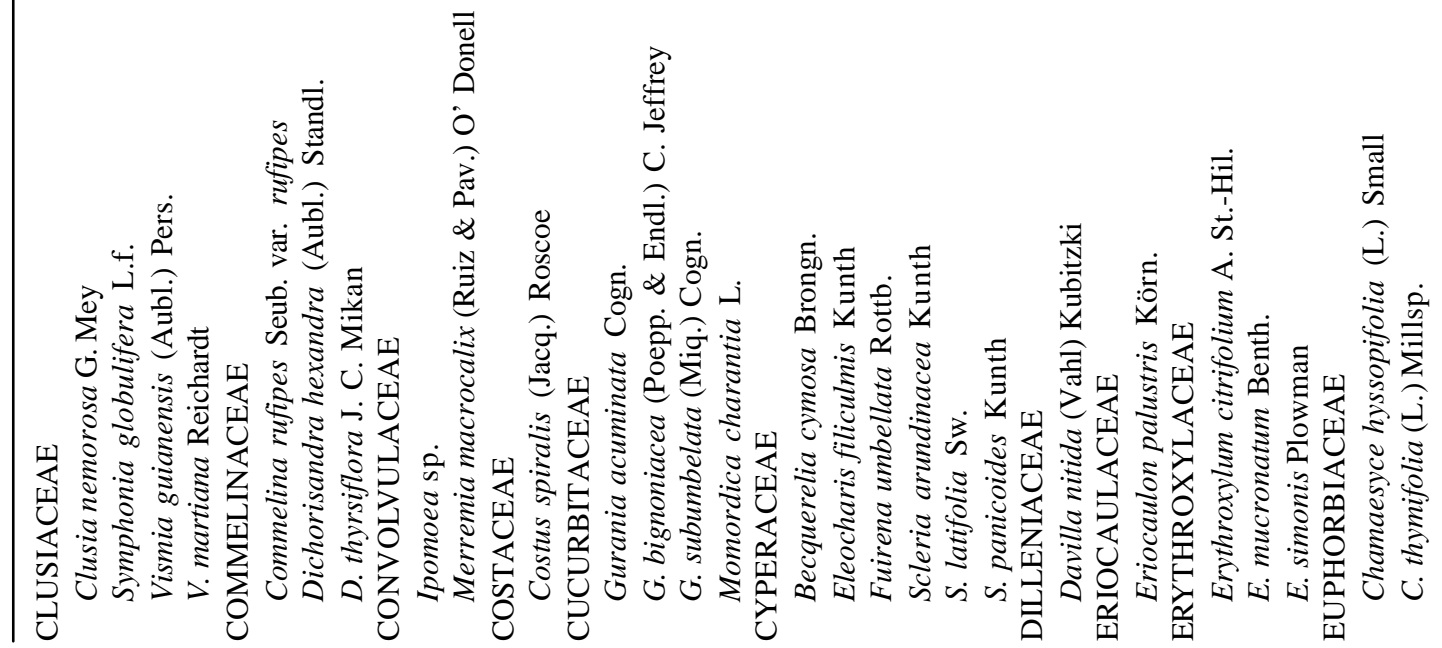




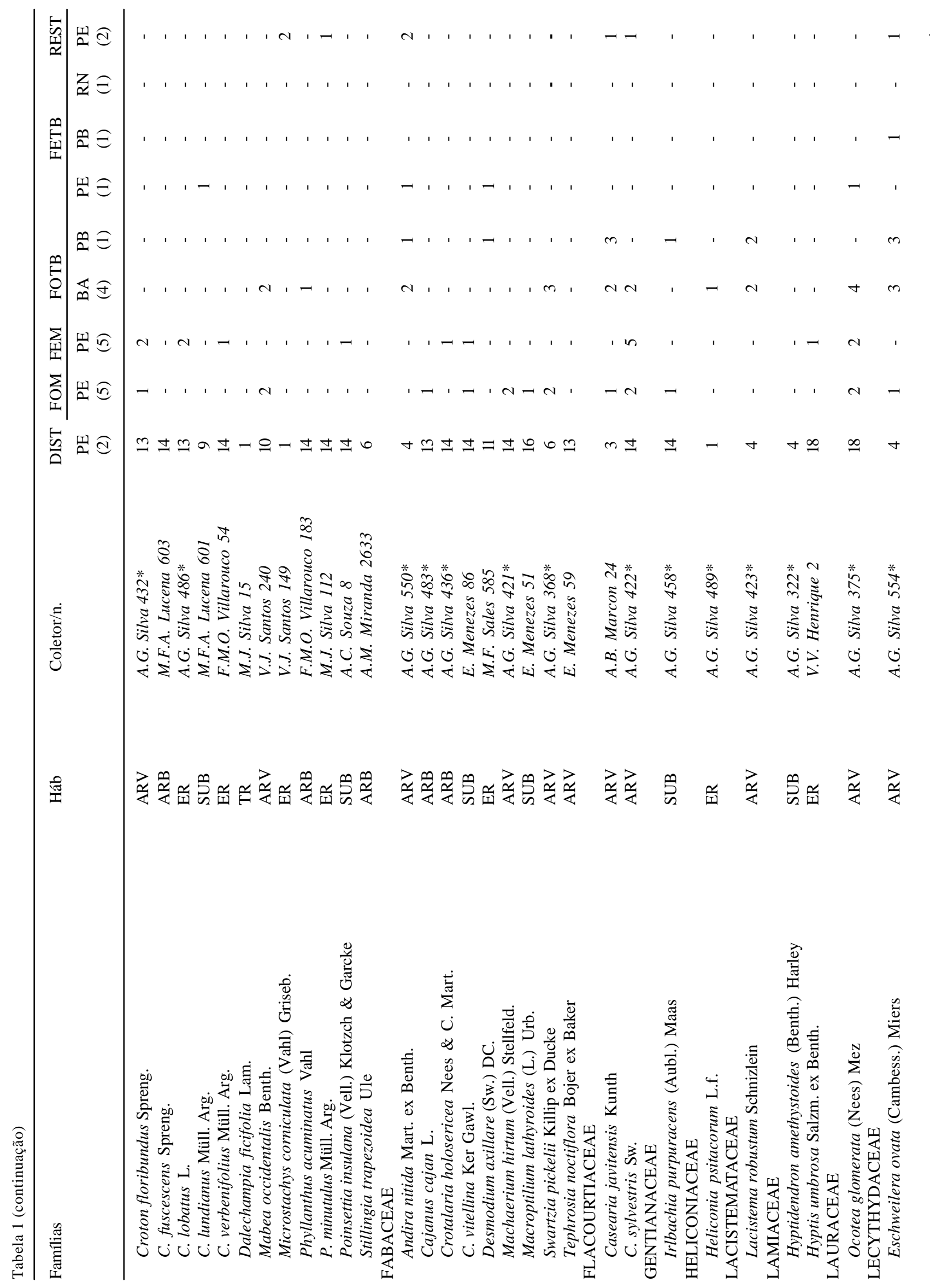


Rodal, Sales, Silva \& Silva: Flora de um Brejo de Altitude na escarpa oriental do planalto da Borborema...

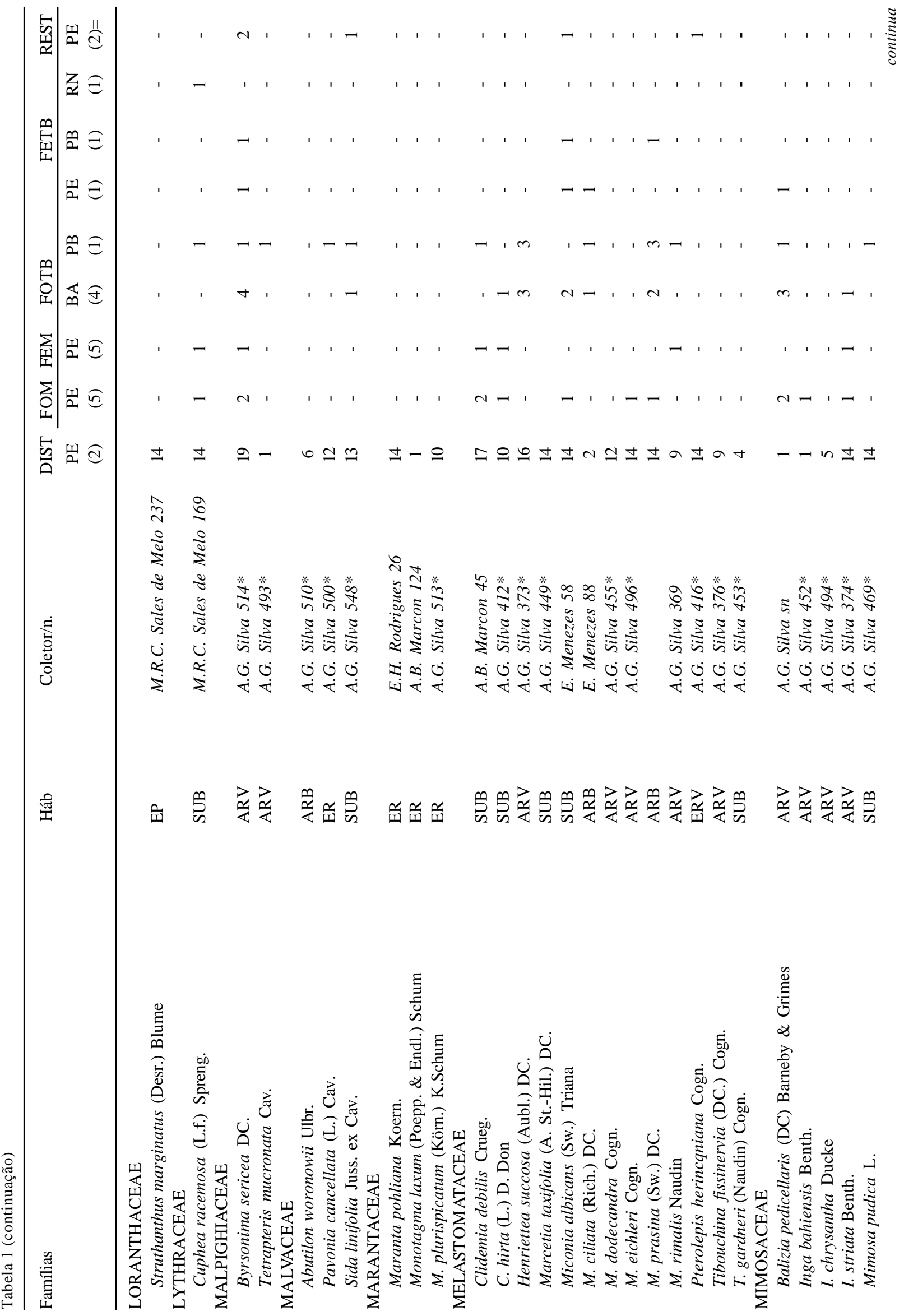




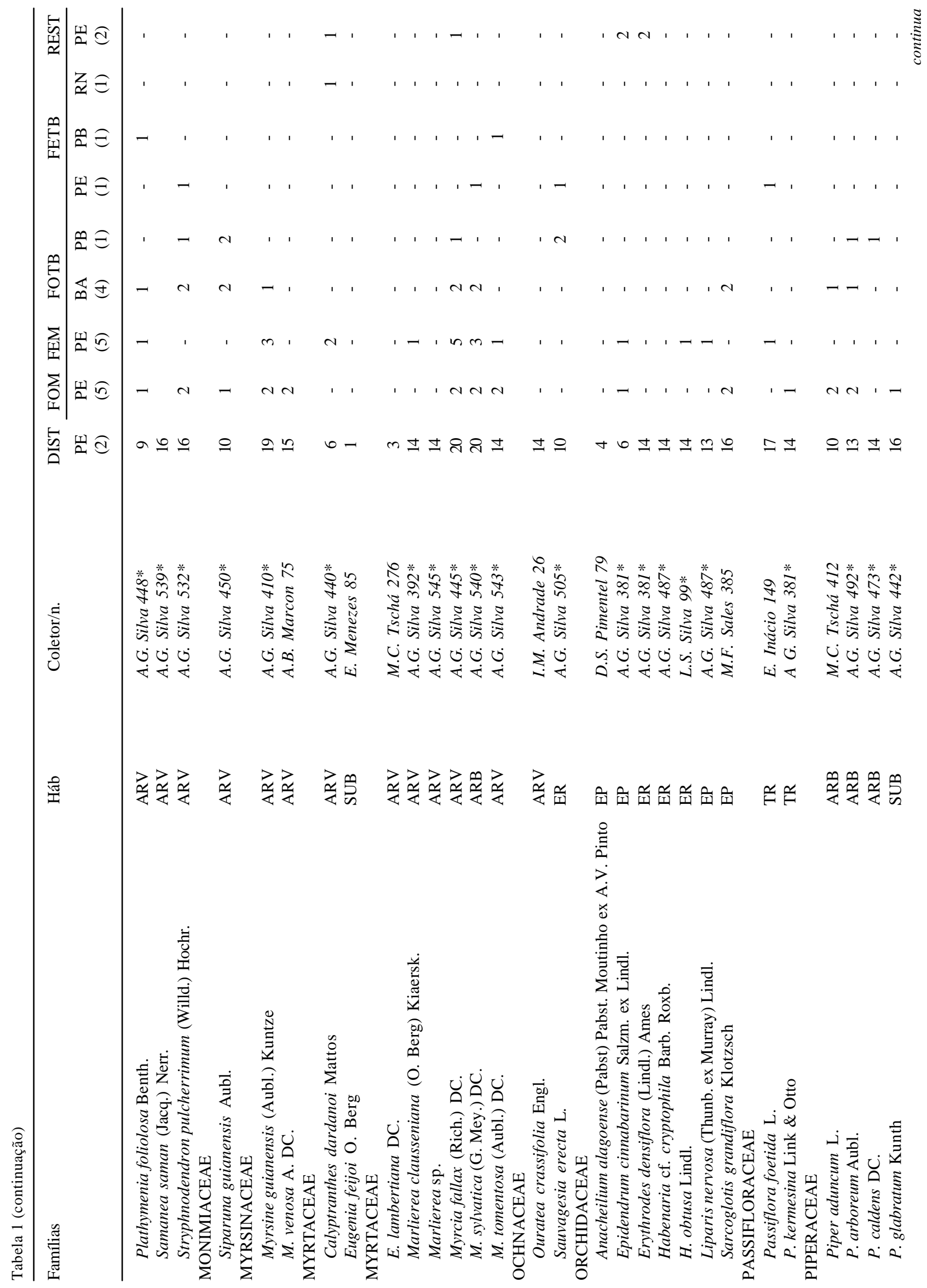




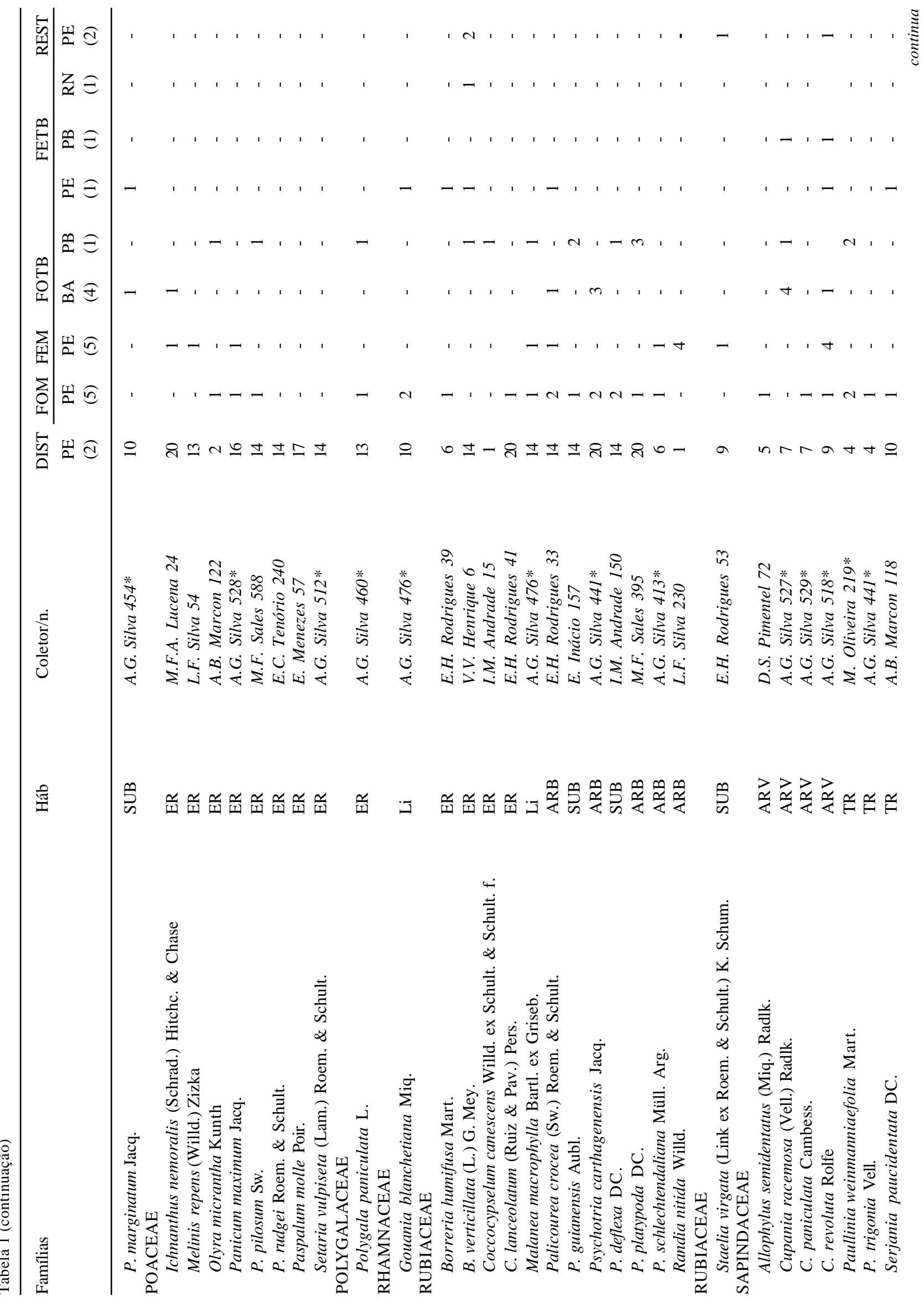




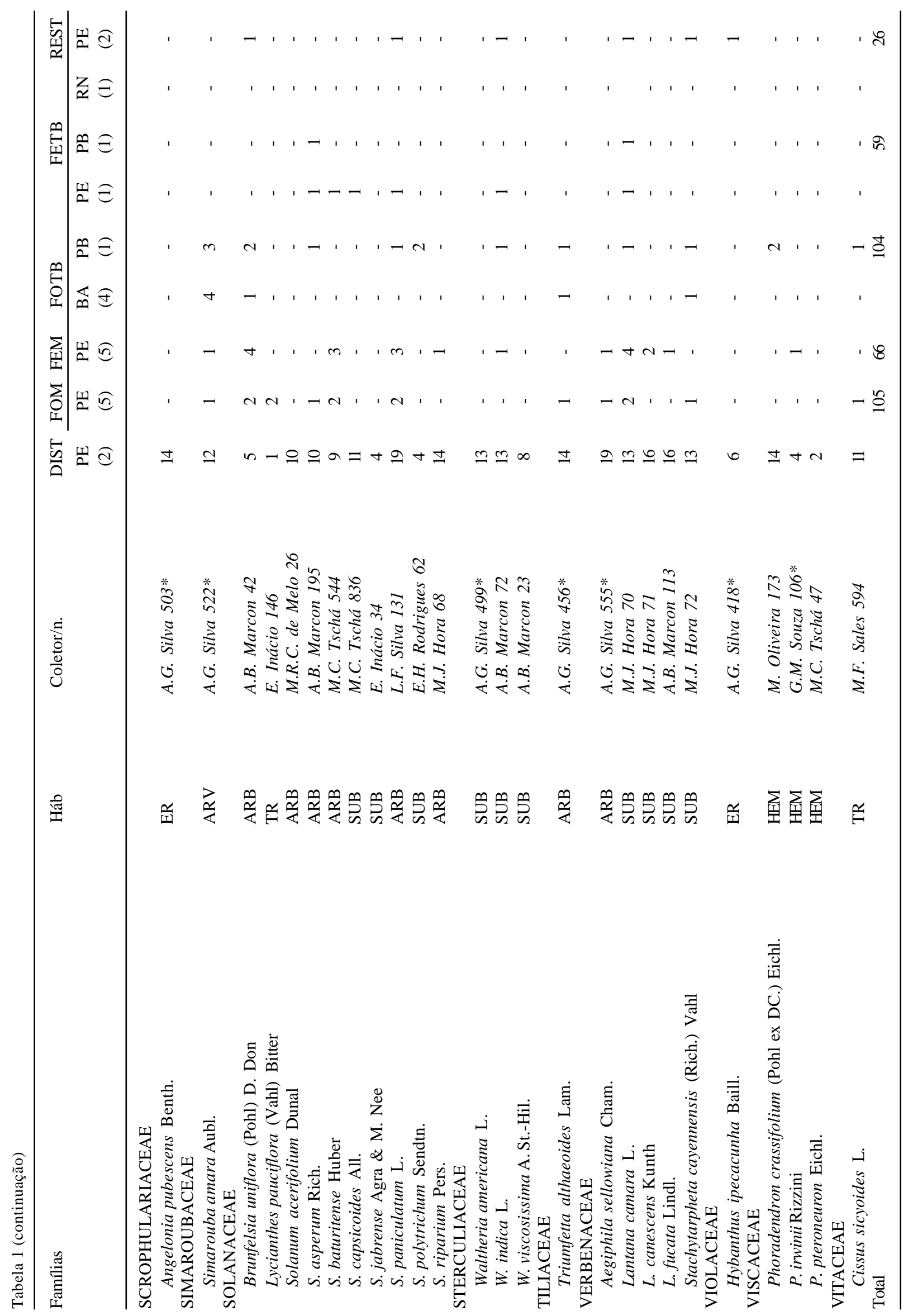


freqüentes, principalmente sobre indivíduos arbustivos e herbáceos de locais abertos enquanto Davilla nitida (Dilleniaceae), Gouania blanchetiana (Rhamnaceae) e as espécies de Gurania (Cucurbitaceae) em geral ocupam a copa de árvores de grande porte, especialmente da borda. Com relação às epífitas foram registradas Anthurium gracile (Araceae) e Epidendrum cinnabarinum (Orchidaceae).

Bonito e outras florestas da região - Das 217 espécies inventariadas, cerca de $50 \%$ ocorreram em outras florestas montanas de Pernambuco e de terras baixas de Pernambuco e Bahia, especialmente as úmidas ou ombrófilas (Tab. 1).

O total de 105 (48\%) espécies são encontradas em duas florestas ombrófilas montanas de Pernambuco. Nas dez florestas ombrófilas de terras baixas analisadas, há 104 espécies em comum (Tab. 1). Em relação aos outros tipos de florestas do estado de Pernambuco, nota-se que 66 espécies (30\%) são também registradas em cinco levantamentos de florestas estacionais montanas.

Considerando ainda as espécies referidas para os fragmentos ombrófilos de Bonito, observa-se que há poucas espécies compartilhadas com as listas provenientes de três florestas estacionais de terras baixas de Pernambuco, Paraíba e Rio Grande do Norte (59) e dois levantamentos em Restinga (26) (Tab. 1).

Padrões de distribuição geográfica das espécies - A maior parte das espécies (cerca de 69,9\%) encontradas nos fragmentos de Bonito tem distribuição exclusiva na América do Sul, ocorrendo desde a porção norte (Colômbia, Venezuela, Guianas, Equador, Peru, Bolívia, norte do Brasil), penetrando na costa leste brasileira e também na porção central do Continente, alcançando a Bolívia e Brasil central. Outra porção representativa (cerca de 26,2\%) distribui-se desde a América Central (Belize, Guatemala, Honduras, Nicarágua, Costa Rica, Panamá) até a porção centro-sul da América do Sul, com raras ocorrendo também na parte sul da América do Norte (Estados Unidos e México). Aproximadamente 20,5\% das espécies têm distribuição relacionada com a costa leste brasileira. Cerca de 7,9\% são exclusivas desta porção; as demais, penetram para oeste ou na região semi-árida (ficando restritas às florestas montanas) ou até o Brasil Central, alcançando parte do Paraguai e leste da Bolívia. De maneira geral, estas plantas habitam principalmente as florestas úmidas a sub-úmidas das Américas central e do sul, algumas têm sua distribuição expandida para tipos vegetacionais mais secos, como Cerrados, florestas estacionais e bosques chiquitanos.
Assim, considerando as espécies de Bonito, foram identificados 20 padrões de distribuição, adotando-se os domínios e províncias propostos por Cabrera \& Willink (1980) para a região neotropical. São apresentados no texto os mais representativos (sete); os demais, são citados apenas na Tab. 1. Padrão Pacífico-Amazônico-Atlântico: inclui 16 espécies com distribuição no domínio Amazônico (províncias Pacífica, Amazônica e Atlântica). Segundo Cabrera \& Willink (1980), a província Pacífica estende-se pelas serras ocidentais baixas dos Andes equatorianos e colombianos, os vales inter-andinos e se prolonga pelas regiões baixas e costas litorâneas da América Central; a província Amazônica inclui norte do Brasil, grande parte das Guianas e Venezuela, leste da Colômbia, Equador, Peru e Bolívia e; a província Atlântica corresponde a faixa litorânea de 50 a $100 \mathrm{~km}$ de largura da costa leste do Brasil, do paralelo $7^{\circ} \mathrm{S}$ a $30^{\circ} \mathrm{S}$. As espécies estudadas com este padrão têm distribuição ao longo das florestas costeiras úmidas dos países centro-americanos e das florestas amazônica e da costa brasileira, destacandose Myrcia fallax e M. sylvatica (Myrtaceae), Siparuna guianensis (Myrsinaceae), Piper aduncum (Piperaceae), Coccocypselum lanceolatume Psychotria carthagenensis (Rubiaceae).

Padrão Atlântico: 17 espécies parecem ter distribuição exclusiva nessa província, como Macroditassa laurifolia (Asclepiadaceae), Bomarea salsilloides (Alstroemeriaceae), Vismia martiana (Clusiaceae), Psychotria schlechtendaliana (Rubiaceae), Andira nitida (Leguminosae latu sensu), entre outras.

Padrão Amazônico-Atlântico: um total de 14 espécies apresenta padrão de distribuição descontínuo, ocorrendo nas florestas úmidas da região amazônica (Venezuela, Colômbia, Equador, Peru, Guianas e norte do Brasil) e da costa atlântica, e estando ausentes na faixa atualmente ocupada por vegetações mais secas, como o cerrado e a caatinga. Destacam-se Thyrsodium spruceanum (Anacardiaceae), Heliconia psitacorum (Heliconiaceae), Ocotea glomerata (Lauraceae), Inga bahiensis e I. striata (Leguminosae latu sensu), Monatagma laxum e Maranta pohliana (Marantaceae), Eugenia feijoi (Myrtaceae), etc. Entretanto, algumas espécies (sete), além de ocorrerem nas províncias Amazônia e Atlântica, penetram ainda na província do Cerrado como Miconia ciliata (Melastomataceae), Myrcia tomentosa (Myrtaceae), Scleria arundinacea (Cyperaceae) e Olyra micrantha (Poaceae).

Padrão Atlântico-Caatinga: 13 espécies têm distribuição principal na província Atlântica, porém 
penetram mais para oeste, até a região semi-árida, ficando restrita apenas aos Brejos de Altitude. Raras podem ser encontradas em outros tipos vegetacionais da província da Caatinga como: Cleome microcarpa (Capparaceae), Bauhinia spicata (Leguminosae latu sensu) e Calyptranthes dardanoi (Myrtaceae).

Padrão Amazônico-Chaquenho-Atlântico: oito espécies compartilham estas três províncias como Anaxagorea dolichocarpa (Annonaceae), Schefllera morotononi (Araliaceae) e Casearia javitensis (Flacourtiaceae). Outras têm distribuição ainda mais ampla alcançando as províncias do Cerrado e da Caatinga como Miconia albicans e Marcetia taxifolia (Melastomataceae).

Padrão Atlântico-Cerrado: seis espécies, especialmente da família Asteraceae, são comuns as províncias do Cerrado e Atlântica como Bacharis oxyodonta, B. rivularis, B. serrulata, Verbesina macrophyla (Asteraceae) além de Cupania paniculata e C. racemosa (Sapindaceae). Outras espécies ainda alcançam a província da Caatinga, onde estão quase restritas aos Brejos de Altitude, como Platymenia foliolosa (Mimosaceae), Miconia rimalis e Tibouchina fissinervia (Melastomataceae) e Solanum baturitense (Solanaceae).

Padrão Atlântico-Cerrado-Chaquenho: são encontradas quatro espécies de ambientes abertos como Emilia forsbergii e Vernonia brasiliana (Asteraceae), Centropogon cornutus (Campanulaceae), Byrsonima sericea (Malpighiaceae).

Pode-se destacar ainda 14 espécies que ocorrem desde o México até a porção centro-sul da América do Sul, provavelmente em tipos vegetacionais mais secos nas províncias Pacífica, Chaquenha, Cerrado e Caatinga, como: Chamaeacrista diphylla, C. nictitans, Samanea saman, Macroptilium lathyroides (Leguminosae latu sensu), Lantana canescens e $L$. fucata (Verbenaceae), etc. Padrão de distribuição pantropical, com as espécies ocorrendo nas Américas e África e ou Ásia, são apresentados por Polygala paniculata (Polygalaceae), Tephrosia noctiflora (Leguminosae latu sensu), Sida linifolia (Malvaceae), Liparis nervosa (Orchidaceae), Piper marginatum (Piperaceae), Waltheria americana e W. indica (Sterculiaceae), Stachytarpheta cayennensis e Lantana camara (Verbenaceae).

\section{Discussão}

Comparando-se a riqueza de táxons arbóreos de Bonito com a de outras florestas do Estado de
Pernambuco (Tab. 2), nota-se que neste trabalho, em Brejo dos Cavalos (Tavares et al. 2000) e em São Vicente Férrer (E.M.N. Ferraz, dados não publicados) há maior riqueza de famílias e espécies que nas ombrófilas de terras baixas, padrão semelhante ao registrado por R.R. Guedes-Bruni (dados não publicados) para o gradiente terras baixas - montanas das florestas ombrófilas do Rio de Janeiro.

Siqueira et al. (2001) salientaram que as famílias arbóreas importantes em florestas ombrófilas da região como: Anacardiaceae, Lecythidaceae, Moraceae, Sapotaceae e Burseraceae tendem a ser menos importantes a medida que as condições vão se tornando mais secas como as registradas nas áreas de florestas estacionais dos levantamentos de L.M. Nascimento (dados não publicados), Ferraz et al. (2003) e Rodal \& Nascimento (prelo). Além disso, deve-se destacar famílias com elevada riqueza de espécies nas ombrófilas montanas como Sapindaceae e Melastomataceae (Tavares et al. 2000; E.M.N. Ferraz, dados não publicados; este trabalho) são pouco representadas nas estacionais montanas (M.E. Correia, dados não publicados; Ferraz et al. 1998; L.M. Nascimento, dados não publicados; Rodal \& Nascimento 2002).

Gentry (1995) observou que dependendo do grau de deficiência hídrica, a flora das florestas neotropicais de determinada área pode ser um subconjunto empobrecido da floresta úmida. Observa-se que quando a deficiência hídrica é mais acentuada, a flora dos brejos de altitude pode representar um conjunto florístico mais empobrecido (Rodal \& Nascimento, prelo) ou similar (Tavares et al. 2000; este trabalho) ao das florestas mais úmidas da região (Guedes et al. 1998; Siqueira et al. 2001). Assim, o fato de haver poucas espécies compartilhadas entre Bonito e fragmentos de florestas estacionais de terras baixas de Pernambuco, Paraíba e Rio Grande do Norte se justifica em função das diferencas de hábitat, especialmente climáticas.

$\mathrm{O}$ reduzido número de levantamentos englobando os componentes não arbóreos dificulta o entendimento dos padrões florísticos da Floresta Atlântica na região. Todavia, nota-se que nas florestas mais secas diminui a proporção de epífitas (Rodal \& Nascimento 2002), provavelmente em função da menor umidade e pela maior penetração de luz, devido ao dossel ser mais aberto.

Dos 43 táxons citados apenas na lista de Bonito a maioria é representada por plantas herbáceas. $\mathrm{O}$ fato de uma parte das listas tratar apenas de levantamentos fitossociológicos dos estratos arbóreo e arbustivo justifica que essas espécies só sejam citadas em Bonito. É 
Tabela 2. Características ambientais e riqueza de espécies em levantamentos quantitativos realizados no Estado de Pernambuco, Brasil. 1-5 ao lado de cada município representa informação a respeito do método empregado. $1=$ diâmetro do caule a altura do peito $>5 \mathrm{~cm}$, $2=$ diâmetro do caule ao nível do solo $>3 \mathrm{~cm}, 3=1$ ha, $4=0,3$ ha, $5=0,1$ ha, NS = número de espécies amostradas. Florestas situadas acima de 600 m.s.m. são consideradas montanas enquanto aquelas abaixo de 100 m.s.m. são de terras baixas.

\begin{tabular}{|c|c|c|c|c|c|c|c|}
\hline Município & Latitude & Longitude & $\begin{array}{l}\text { Altitude } \\
\text { (m) }\end{array}$ & $\begin{array}{l}\text { Precipitação } \\
\left(\mathrm{mm} \operatorname{ano}^{-1}\right)\end{array}$ & Geomorfologia & NS & Referência \\
\hline & & & & & Florestaombrófila & & \\
\hline Recife $(1,3)$ & $8^{\circ} 03^{\prime}$ & $34^{\circ} 56^{\prime}$ & $30-50$ & 2.243 & Planície costeira & 56 & $\begin{array}{l}\text { Lins e Silva \& Rodal } \\
\text { (prelo) }\end{array}$ \\
\hline $\begin{array}{l}\text { Cabo de Santo Agostinho } \\
\quad(1,3)\end{array}$ & $8^{\circ} 15^{\prime}$ & $35^{\circ} 02^{\prime}$ & $20-80$ & 2.143 & Planície costeira & 82 & Siqueira et al. (2001) \\
\hline \multirow[t]{2}{*}{ Caruaru $(1,3)$} & $8^{\circ} 17$ & $35^{\circ} 58^{\prime}$ & $900-1.000$ & 1.020 & Encosta Leste da Borborema & 93 & Tavares et al. (2000) \\
\hline & & & & & Floresta estacional & & \\
\hline $\begin{array}{l}\text { São Lourenço da Mata } \\
\quad(1,3)\end{array}$ & $8^{\circ} 02^{\prime}$ & $35^{\circ} 07^{\prime}$ & 900 & 1.301 & Encosta Leste da Borborema & 88 & $\begin{array}{l}\text { Andrade \& Rodal } \\
\text { (2004) }\end{array}$ \\
\hline $\begin{array}{l}\text { Brejo da Madre de Deus } \\
\quad(1,3)\end{array}$ & $8^{\circ} 21$ & $36^{\circ} 28^{\prime}$ & $900-950$ & 900 & Planalto da Borborema & 62 & $\begin{array}{l}\text { L.M. Nascimento } \\
\text { (dados não publicados) }\end{array}$ \\
\hline Triunfo $(2,5)$ & $7^{\circ} 52^{\prime}$ & $38^{\circ} 17^{\prime}$ & 900 & 1.000 & Encosta Oeste da Borborema & 53 & Ferraz et al. (2003) \\
\hline Serra Negra $(1,3)$ & $8^{\circ} 35$ & $38^{\circ} 04^{\prime}$ & $930-940$ & 900 & $\begin{array}{l}\text { Montanhas baixas da } \\
\text { depressão semi-árida }\end{array}$ & 52 & $\begin{array}{l}\text { Rodal \& Nascimento } \\
\text { (prelo) }\end{array}$ \\
\hline Betânia $(2,5)$ & $8^{\circ} 16^{\prime}$ & $30^{\circ} 09^{\prime}$ & 690 & 510 & Depressão semi-árida & 33 & $\begin{array}{l}\text { Rodal et al. (dados não } \\
\text { publicados) }\end{array}$ \\
\hline Jataúba $(2,4)$ & $8^{\circ} 10^{\prime}$ & $36^{\circ} 40^{\prime}$ & $1.020-120$ & 764 & Planalto da Borborema & 106 & Moura \& Sampaio ( 2001) \\
\hline \multirow[t]{2}{*}{ Pesqueira $(2,4)$} & $8^{\circ} 22^{\prime}$ & $36^{\circ} 42^{\prime}$ & $860-880$ & 885 & Planalto da Borborema & 65 & $\begin{array}{l}\text { M.E. Correia (dados não } \\
\text { publicados }\end{array}$ \\
\hline & & & & & Caatinga & & \\
\hline Serra Talhada $(2,5)$ & $7^{\circ} 59$ & $38^{\circ} 19^{\prime}$ & 700 & 639 & Depressão semi-árida & 23 & Ferraz et al. (2003) \\
\hline Betânia $(2,5)$ & $8^{\circ} 18^{\prime}$ & $30^{\circ} 11^{\prime}$ & 500 & 510 & Depressão semi-árida & 21 & $\begin{array}{l}\text { Rodal } \text { et al. (dados não } \\
\text { publicados) }\end{array}$ \\
\hline
\end{tabular}

provável que essas espécies também ocorram em outros locais visto serem plantas comuns na região como: Conyza bonariensis, Emilia sonchifolia (Asteraceae), Cordia multispicata (Boraginaceae), Becquerelia cymosa e Scleria latifolia, (Cyperaceae), Chamaesyce hyssopifolia, Croton lobatus, Microstachys corniculata (Euphorbiaceae), Pavonia cancellata (Malvaceae), Borreria verticillata, Coccocypselum lanceolatum, Psychotria platypoda (Rubiaceae), Stachytarpheta cayennensis (Verbenaceae) e Polygala paniculata (Polygalaceae).

A maioria das espécies listadas nos fragmentos florestais de Bonito apresenta ampla distribuição, ocorrendo desde os países centro-americanos e porções norte e leste da América do Sul, em geral habitando as florestas úmidas a subúmidas. Quando se questiona a possibilidade da flora atual das florestas montanas terem porção significativa de elementos amazônicos, constatase que das espécies que mostram padrão exclusivamente amazônico-atlântico, poucas habitam as florestas de terra firme como Thyrsodium spruceanum (Anacardiaceae),
Monatagma laxum (Marantaceae), Gurania bignoniacea (Cucurbitaceae) (Ribeiro et al. 1999); as demais parecem ser plantas de ambientes mais secos e ou pertubados dentro da província Amazônica.

Outro conjunto parece ser formado por espécies $(15,9 \%)$ com distribuição sul-americana, em ambientes mais secos como forestas semi-decíduas a decíduas, cerrados, bosque seco chiquitano e bosque serrano chaquenho (Killeen et al. 1993), nas províncias Chaquenha, do Cerrado e da Caatinga. As províncias da Caatinga e Chaquenha, de acordo com Cabrera \& Willink (1980), fazem parte do domínio Chaquenho, que ocupa área atualmente disjunta, mas que em eras geológicas anteriores talvez estivessem unidas. Praticamente não foram encontradas espécies cuja distribuição principal fosse na porção sul do continente sul-americano (província Paranense, que ocupa a porção sul do Brasil, nordeste da Argentina e leste do Paraguai), com exceção de Croton verbenifolius (Euphorbiaceae), Cuphea racemosa (Lythraceae) e Myrsine venosa (Myrsinaceae). 
Os resultados mostram que a flora angiospérmica de Bonito é compartilhada com outras florestas ombrófilas da região, quer sejam montanas ou de terras baixas. Isso revela clara unidade florística Atlânticonordestina. Pode-se concluir ainda que as ombrófilas da região tem flora mais relaciona com o norte do continente sul-americano e América Central.

\section{Referências bibliográficas}

Alcoforado-Filho, F.G.; Sampaio, E.V.S.B. \& Rodal, M.J.N. 2003. Florística e fitossociologia de um remanescente de vegetação caducifólia espinhosa em Caruaru, Pernambuco. Acta Botanica Brasilica 17: 287-303.

Andrade, K.V.S \& Rodal, M.J.N. 2004. Fisionomia e estrutura de um remanescente de floresta estacional semidecidual de terras baixas no nordeste do Brasil. Revista Brasileira de Botânica 27: 463-474.

Andrade-Lima, D. 1982. Present-day forest refuges in northeastern Brazil. Pp. 247-251. In: G.T. Prance (ed.). Biological diversification in the tropics. New York, Columbia University Press.

Cabrera, A.L. \& Willink, A. 1980. Biogeografia de América Latina. Washington, D.C, Secretaria Geral de la Organización de los Estados Americanos. (Série de Biologia, Monografia n. 13).

Cestaro, L.A. \& Soares, J.J. 2004. Variações florística e estrutural e relações fitogeográficas de um fragmento de floresta decídua no Rio Grande do Norte. Acta Botanica Brasilica 18: 203-218.

Cronquist, A. 1981. An integrated system of classification of flowering plants. New York, Columbia University Press.

Ferraz, E.M.N.; Rodal, M.J.N.; Sampaio, E.V.S.B. \& Pereira, R.C.A. 1998. Composição florística em trechos de vegetação de Caatinga e brejo de altitude na região do Vale do Pajeú, Pernambuco. Revista Brasileira de Botânica 21: 7-15.

Ferraz, E.M.N.; Rodal, M.J.N. \& Sampaio, E.V.S.B. 2003. Physiognomy and structure of vegetation along an altitudinal gradient in the semi-arid region of northeastern Brazil. Phytocoenologia 33: 71-92.

Gentry, A.H. 1995. Diversity and floristic composition of neotropical dry forests. Pp. 146-194. In: S.H. Bullock; H.A. Mooney \& E. Medina (eds.). Seasonally dry forests. Cambridge, Cambridge University Press.

Guedes, M.L.S. 1998. A vegetação fanerogâmica da Reserva Ecológica de Dois Irmãos. Pp. 157-172. In: I.C.S. Machado; A.V. Lopes \& K.C. Porto (orgs.). Reserva Ecológica de Dois Irmãos: estudos em um remanescente de Mata Atlântica em área urbana (Recife - Pernambuco Brasil). Recife, Editora Universitária da Universidade Federal de Pernambuco.

Jacomine, P.T.; Cavalcanti, A.C.; Burgos, N.; Pessoa, S.C.P. \& Silveira, C.O. 1973. Levantamento exploratórioreconhecimento de solos do estado de Pernambuco. v.1. Recife, SUDENE/Divisão de Pesquisa Pedológica. (Boletim Técnico 26, Pedologia 14.).
Killeen, T.J.; Garcia, E. \& Beck, S.G. 1993. Guia de arboles de Bolivia. La Paz, Herbário Nacional de Bolívia - Missouri BotanicalGarden.

Lins e Silva, A.C.B. \& Rodal, M.J.N. (no prelo). Tree community structure in an Urban Atlantic Forest Rennant in Pernambuco, Brazil. Memoir of New York Botanical Garden.

Mori, S.A.; Silva, L.A.M.; Lisboa, G. \& Coradin, L. 1989. Manual de manejo do Herbário Fanerogâmico. Ilhéus, Centro de Pesquisas do Cacau.

Moura, F.B.P. \& Sampaio, E.V.S.B. 2001. Flora lenhosa de uma mata serrana semidecídua em Jataúba, Pernambuco. Revista Nordestina de Biologia 15: 77- 89.

Myers, N.; Mittermeier, R.A.; Mittermeier, C.G.; Fonseca, G.B. $\&$ Kents, J. 2000. Biodiversity hotspots for conservation priorities. Nature 403: 853-858.

NYBG 2004a. Checklist of Monte Pascoal National Park. http:/ /www.nybg.org/bsci/res/bahia/Checkli1.html. Acessoem: 22 de março de 2004.

NYBG 2004b. Checklist of Serra Grande forest/Serra do Condurú State Park. http://www.nybg.org/bsci/res/bahia / Checkli1.html. Acesso em: 22 de março de 2004.

NYBG 2004c. Checklist of Mata da Esperança. http:// www.nybg.org/bsci/res/bahia/ME-chkl.html. Acesso em: 22 de março de 2004.

NYBG 2004d. Checklist of Una Biological Reserve. http:// www.nybg.org/bsci/res/bahia/Checkli1.html. Acesso em: 22 de março de 2004.

Oliveira-Filho, A.T. \& Ratter, J.A. 2000. Padrões florísticos das matas ciliares da região do Cerrado e a evolução das paisagens do Brasil central durante o quaternário tardio .Pp. 73-90. In: R.R. Rodrigues \& H.F. Leitão-Filho (eds.). Matas ciliares: conservação e recuperação. São Paulo, EDUSP.

Ribeiro, J.E.L.S.; Hopkins, M. J. G. \& Vicentini, A. 1999. Flora da Reserva Ducke - Guia de identificação das plantas vasculares de uma floresta de terra-firme na Amazônia Central. Manaus, INPA- DFID.

Rizzini, C.T. 1979. Tratado de Fitogeografia do Brasil: aspectos florísticos e sociológicos. v.2. São Paulo, HUCITEC.

Rodal, M.J.N. 2002. Montane forests in Northeast Brazil: a phytogeographical approach. Botanishe Jahrbücher für Systematik, Pflanzengeschichte und Pflanzengeographie 124: $1-10$.

Rodal, M.J.N. \& Nascimento, L. M. 2002. Levantamento florístico da floresta serrana da Reserva Biológica de Serra Negra, microrregião de Itaparica, Pernambuco, Brasil. Acta Botanica Brasilica 16: 481-500.

Rodal, M.J.N. \& Nascimento, L.M. prelo. The arboreal component of a dry forest in Northeastern Brazil. Brazilian Journal of Biology 67(4).

Rodal, M.J.N. \& Sales, M.F. (no prelo). Panorama of the Montane Forests of Pernambuco State, Brazil. Memoir of New York Botanical Garden.

Rodal, M.J.N.; Sales, M.F. \& Mayo, S.J. 1998. Florestas serranas de Pernambuco: localização e diversidade dos remanescentes dos Brejos de Altitude. Recife, Imprensa Universitária da Universidade Federal Rural de Pernambuco. 
Sales, M.F.; Mayo, S.J. \& Rodal, M.J.N. 1998. Florestas serranas de Pernambuco: um checklist da flora ameaçada dos Brejos de Altitude. Recife, Imprensa Universitária da Universidade Federal Rural de Pernambuco.

Silva, A.G. 2004. Fisionomia e estrutura do componente arbóreo em um gradiente altitudinal na Mata da Usina São José, Igarassu, Pernambuco. Dissertação de Mestrado. Universidade Federal Rural de Pernambuco, Recife.

Siqueira, D.R.; Rodal, M.J.N.; Lins e Silva, A.C.B. \& Melo, A.L. 2001. Physiognomy, structure and floristic in na area of Atlantic Forest in Northeast Brazil. Pp. 315-331. In: G.

Gottsberger \& S. Lied (eds.). Stuttgart, Proccedings of Life Forms and Strategies in Tropical Forests, Ulmer Verlag.
Siqueira, M.F. 1994. Análise florística e ordenação de espécies arbóreas da Mata Atlântica através de dados binários. Dissertação de Mestrado. Universidade Estadual de Campinas, Campinas.

Tavares, M.C.G.; Rodal, M.J.N.; Melo, A.L. \& Araújo, M.F. 2000. Fitossociologia do componente arbóreo de um trecho de Floresta Ombrófila Montana do Parque Ecológico João Vasconcelos Sobrinho, Caruaru, Pernambuco. Naturalia25: 17-32.

Veloso, H.P.; Rangel-Filho, A.L.R. \& Lima, J.C.A. 1991. Classificação da vegetação brasileira, adaptada a um sistema universal. Rio de Janeiro, IBGE (Departamento de Recursos Naturais eEstudos Ambientais). 